\title{
SISTEM PAKAR PENGENALAN BAKAT DAN MINAT ANAK DENGAN METODE FORWARD CHAINING
}

\author{
Siti Uzlifatul Asma ${ }^{1)}$ Muhyiddin Zainal Arifin ${ }^{2)}$ Tholib Hariono $^{3)}$ \\ ${ }^{1,2,3)}$ Fakultas Teknologi Informasi Universitas KH.A. Wahab Hasbullah \\ Correspondence Author : harionotholib@gmail.com
}

\begin{abstract}
Every human being has an interest, and a different talent. Interest is a strong impetus for a person to do something he wants. Talent itself is an existing ability or innate or the ability that can be trained to master the things that interest. The potential of the child should be stimulated in advance so that it can be seen as a skill, knowledge and skillfulness that becomes the provision of his life. One way to recognize the child's talents and interests requires a test to understand the temperament and personality of the child, to understand multiple intelligences and to recognize the direction of the child's interest. The test is applied to an expert system using the Forward Chaining method to help determine the type of intelligence in the child. Each type of child intelligence has several potential talents and special interests of the child. The expert system is implemented in a Visual Basic 6.0 programming language. The results of this study in obtaining an alternative decision to recognize the type of intelligence of children who show potential talents and interests of children. So that talent can be further developed.
\end{abstract}

\section{Keywords: Talent and Interests, Forward Chaining, Expert System}

\section{INTISARI}

Setiap manusia memiliki minat, dan bakat yang berbeda. Minat merupakan dorongan yang kuat bagi seseorang untuk melakukan sesuatu yang menjadi keinginannya. Bakat sendiri merupakan kemampuan yang sudah ada atau bawaan sejak lahir atau kemampuan yang bisa dilatih untuk bisa menguasai hal yang diminati. potensi anak harus dirangsang terlebih dahulu sehingga dapat terlihat sebagi suatu kecakapan, pengetahuan dan keterampilankhusus yang menjadi bekal hidupnya. salah satu cara mengenali bakat dan minat anak dibutuhkan suatu tes untuk memahami temperamen dan kepribadian anak, memahami kecerdasan majemuk serta mengenali arah minat anak. Tes diterapkan pada sebuah sistem pakar dengan menggunakan metode Forward Chaining untuk membantu mengetahui jenis kecerdasan pada anak. Setiap jenis kecerdasan anak memiliki beberapa potensi bakat dan minat khusus anak. Sistem pakar tersebut diimplementasikan pada sebuah bahasa pemrograman Visual Basic 6.0. Hasil dari penelitian ini di peroleh keputusan alternatif untuk mengenal jenis kecerdasan anak yang menunjukkan potensi bakat dan minat anak. Sehingga bakat tersebut dapat lebih dikembangkan.

Kata kunci: Bakat dan Minat, Forward Chaining, Sistem Pakar 


\section{PENDAHULUAN}

Minat merupakan dorongan yang kuat bagi seseorang untuk melakukan segala sesuatu yang menjadi keinginannya, yang dapat mengarahkan bakat dan keberadaannya merupakan faktor utama dalam pengembangan bakat. Bakat sendiri merupakan kemampuan yang sudah ada atau dibawa sejak lahir atau kemampuan yang bisa dilatih untuk bisa menguasai hal yang diminati (Ahmadi dan Soleh,2005). Dengan kata lain setiap anak dianugrahi minat dan bakat yang berbeda-beda satu dengan yang lain yang harus dirangsang terlebih dahulu sehingga dapat terlihat sebagi suatu kecakapan, pengetahuan dan keterampilankhusus yang menjadi bekal hidupnya kelak. Sehingga bakat akan benar-benar terealisasi jika telah ditunjang dengan minat, latihan, pengetahuan, pengalaman agar bakat terssebut dapat teraktualisasi dengan baik. Maka salah satu cara mengenali bakat dan minat anak dibutuhkan suatu tes untuk memahami temperamen dan kepribadian anak, memahami kecerdasan majemuk serta mengenali arah minat anak. Sehingga akan lebih mudah bagi orang tua untuk mengarahkan bakat dan minat anak. Suatu tes pengenalan bakat dapat diterapkan pada sebuah sistem pendukung keputusan untuk membantu mengetahui hasil tes yang diinginkan. Dalam proses komputerisasi ini bisa menggunakan Sistem Pendukung Keputusan yang selanjutnya akan menjadi pembahasan dalam penelitian ini.

\section{Kerangka Teori}

\subsection{Landasan Teori}

\subsubsection{Sistem pakar}

Menurut Mc Leod mendefinisikan sistem sebagai suatu integrasi elemenelemen yang semuanya bekerja menuju satu tujuan. Semua sistem meliputi tiga elemen utama :input, transformasi dan output.MacLeod mendefinisikan informasi sesebagai data yang yang telah diolah menjadi bentuk yang berarti bagi penerimanya. Alat pengolah informasi dapat meliputi elemen komputer, elemen non komputer atau kombinasi dari keduanya.

Istilah sistem pakar berasal dari istilah knowledge-based expert system. Istilah knowledge-based expert system muncul karena untuk memasukkan masalah, sistem pakar menggunakan pengetahuan seorang pakar yang dimasukkan ke dalam komputer. Seseorang yang bukan pakar menggunakan sistem pakar untuk meningkatkan kemampuan pemecahan masalah, sedangkan seorang akar menggunakan sistem pakar untuk knowledge assistant. Sistem pakar adalah sebuah program komputer yang menyamai kemampuan pengambilan keputusan dan kemampuan pemecahan masalah dari seorang pakar.

Forward chaining adalah teknik pencarian yang dimulai dengan fakta yang diketahui, kemudian mencocokan fakta-fakta tersebut dengan bagian IF dari rules IF-THEN. Jika ada fakta yang cocok dengan bagian IF, maka rule tersebut dieksekusi. Bila sebuah rule dieksekusi maka sebuah fakta baru (bagian THEN) ditambahkan ke dalam database. Setiap kali pencocokan, dimulai dari rule teratas. Setiap rule hanya boleh dieksekusi sekali saja. Proses pencocokan berhenti bila tidak ada lagi rule yang bisa dieksekusi. Pada metode ini, data digunakan untuk menentukan aturan mana yang akan dijalankan. Metode inferensi forward chaining cocok digunakan untuk menangani masalah pengendalian (controlling) dan peramalan (prognosis).

\subsubsection{Bakat dan minat}

Secara umum bakat merupakan kemampuan potensial yang dimiliki seseorang untuk mencapai keberhasilan di masa yang akan datang. Kemampuan potensial itu baru akan terealisasi menjadi kecakapan yang nyata sesudah belajar atau berlatih. Pada perkembangan selanjutnya, bakat diartikan sebagai kemampuan individu untuk melakukan tugas tertentu tanpa banyak bergantung pada upaya pendidikan dan pelatihan. Itulah yang kemudian disebut 
sebagai bakat khusus (specific aptitude) atau tale nta (talent) yang oleh sejumlah pakar tidak dapat dipelajari karena merupakan karunia dari Tuhan Yang Maha Esa sebagai pembawaan sejak lahir.

Minat merupakan faktor psikologis yang mempengaruhi tindakan seseorang. Pada semua usia, minat memainkan peran penting dalam kehidupan seseorang dan mempunyai dampak yang besar atas perilaku dan sikap. Pada minat terkandung beberapa unsur-unsur sebagai berikut:

a. Adanya sesuatu yang memberi stimulus,

b. Adanya kesediaan jiwa yang menerima stimulus,

c. Berlangsungnya dalam waktu yang cukup lama

\subsubsection{Visual Basic 6.0}

Visual Basic adalah sebuah alat yang memungkinkan kita untuk membuat aplikasi berbasis Windows GUI (Graphical User Interface). Aplikasi yang dihasilkan mirip seperti aplikasi-aplikasi windows lainnya, seperti MS Word, MS Excel, Wordpad, dan sejenisnya, sehingga user yang terbiasa bekerja di lingkungan windows akan cepat menguasai aplikasi yang kita buat nantinya.

Aplikasi yang dibuat dengan Visual Basic bekerja berdasarkan event-event. Contoh event : user klik tombol, pilih menu, dll. Jadi ketika tidak ada event yang terjadi (user tidak melakukan apa-apa), aplikasi berada dalam kondisi tidak aktif.

Dengan adanya event, maka dapat mengerjakan aplikasi per event. Jika satu event sudah berjalan dengan benar, kerjakan event yang lain. Dengan demikian cara ini membuat aplikasi menjadi modular (kerjakan event 1 , event 2 , event 3 , dst sehingga menjadi aplikasi yang sebenarnya). Cara ini juga memudahkan kita untuk men-debug program apabila terjadi kesalahan.

Visual Basic berjalan pada 3 mode :

a. Mode Design, dalam modus inilah pembuatan aplikasi dilaksanakan

b. Mode Run, dalam mode ini aplikasi dijalankan.

c. Mode Break, dalam mode ini aplikasi di hentikan sementara mengaktifkan

Visual Basic Debugger (untuk mendebug program, biasanya dilakukan untuk melacak kesalahan/error).

\subsubsection{Microsoft Access 2007}

Microsoft Access 2007 adalah aplikasi yang digunkan untuk membuat database. Didalam Microsoft Access 2007 ada 6 buah objek yang biasa digunakandalam sebuah pengolahan database.

1. Tabel yaitu object yang digunakan untuk membuat tabel yang akan digunakan dalam file database, untuk menyimpan data tiap informasi yang terimpan.

2. Query yaitu object yang digunakan untuk menampilkan, menyunting dan menganalisis suatu data dengan cara lain.

3. Form yaitu object database yang digunakan untuk membuat kontrolkontrol untuk proses memasukkan, memeriksa dan memperbarui data.

4. Report mengubah data menjadi dokumen. Report dapat berupaberbagai macam bentukdan ukuran tapi semua didesain untuk menampilkan data yang dicetak.

5. Page yaitu objek khusus yang digunakan untuk menamppilkan dan bekerja dengan data yang diambil dari internet atau intranet.

6. Macro merupakan rangkaian dari beberapa perintah yang dapat disimpan dan dijalankan ulang secara otomatis, misalnya : membuka sebuah form, mencetak report dan sebagainya. 


\subsection{Pustaka Rujukan}

Pengembangan kecerdasan anak dapat diketahui dengan konsultasi kepada ahlinya, yaitu seorang psikolog. Namun untuk konsultasi dengan psikolog membutuhkan waktu dan biaya yang cukup mahal. Hal ini menjadi salah satu penyebab orang tua tidak memperhatikan perkembangan kecerdasan anak. (Amalia Putri Setyawan, 2016).

Saat ini masih banyak orang tua dan guru sebagai penanggung jawab dalam keberlangsungan pendidikan anak yang belum mengetahui bakat pada anak mereka. Terbatasnya jumlah pakar untuk berkonsultasi tentang bakat anak merupakan salah satu penyebab hal ini. Sistem pakar bisa digunakan karena sistem pakar adalah sistem yang menggunakan pengetahuan, fakta, dan teknik penalaran untuk pemecahan masalah akan memindahkan kemampuan pakar tersebut ke dalam computer. (Febi Nur Salisah, 2015).

\section{Metodologi}

\subsection{Alat dan Bahan}

3.1.1 Kebutuhan Perangkat Keras

Untuk mendukung perancangan sistem yang akan dibuat penulis menggunakan beberapa perangkat keras dengan fungsinya masing-masing yaitu Komputer AMD C-60 APU dengan Radeon TM HD Graphics $1.00 \mathrm{GHz}$, Memory (RAM) 2.00 GB dan Sistem Operasi Windows 7 Ultimate

3.1.2 Kebutuhan Perangkat Lunak

Untuk menunjang pengaplikasian hardware maka dibutuhkanlah perangkat lunak (software). Selain untuk mengoptimalkan hardware, perangkat lunak juga digunakan sebagai penunjang aplikasi yang akan digunakan.

Kebutuhan perangkat lunak yang diperlukan untuk kelancaran perancangan sistem meliputi, Microsoft Visual Basic 6.0 sebagai bahasa pemrograman yang digunakan dan Microsoft Access 2007 untuk database.

\subsection{Prosedur Penelitian}

Penelitian ini merupakan penelitian pengembangan (development research) dengan maksud untuk mengembangkan pengetahuan tentang sistem pakar pengenalan bakat dan minat anak. Metode penelitian untuk menyelesaikan permasalahan ini adalah sebagai berikut:

1. Studi literatur,

2. Pengumpulan data

a. Data yang dikumpulkan antara lain diperoleh dari RA Darul Muta'allimin Patianrowo

b. Data kuesioner yang diperoleh dari siswa-siswi RA Darul Muta'allimin Patianrowo

3. Pengolahan data

Adapun alur pengolahan data dapat dilihat pada gambar berikut : 


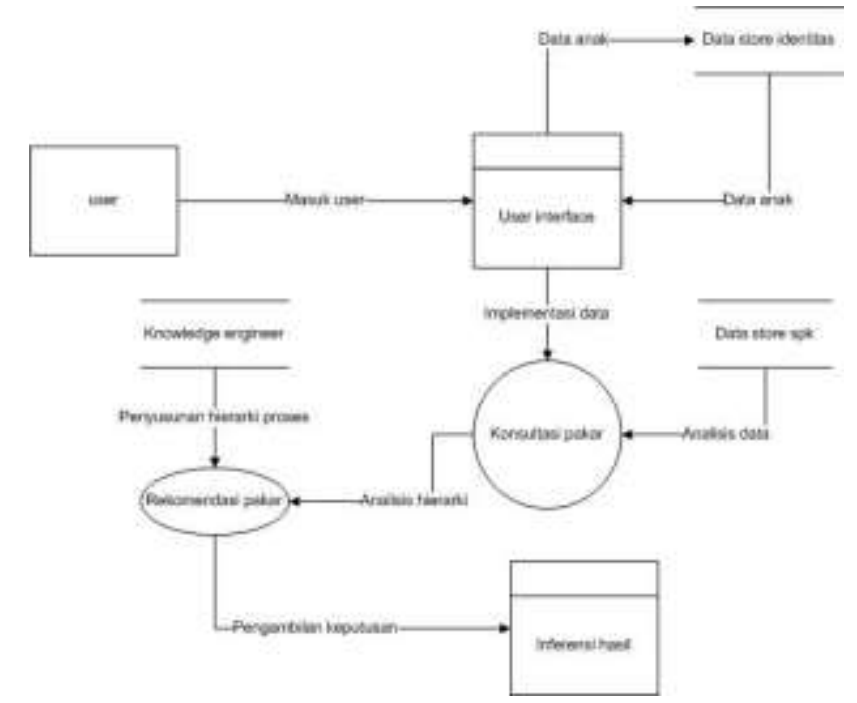

Gambar 1 Gambar Alur Pengolahan Data

\section{Kuisioner}

Kuisioner dilakukan untuk menghitung derajat keanggotaan terhadap kriteria penilaian yang dibuat sedemikian rupa sehingga mudah dipahami agar tidak terjadi atau meminimalkan kesalahpahaman dan ketidakjelasan dalam pengisiannya.

\subsection{Perancangan Sistem}

Dalam perancangan Sistem Pakar Pengenalan Bakat dan Minat Anak ini penulis menggunakan Flowchart dan DFD. Yang digunakan untuk menentukan atau menggambarkan alur sistem software yang terkait dengan objek.

a. Flowchart system

Alur pengelolaan system mengharuskan pengguna melakukan penginputan data anak yang akan dicari tahu jenis bakatnya. User dapat melakukan tes berdasarkan usia anak yaitu antara rentang 6-9 tahun dan 10-18 tahun. Setelah dilakukan tes system akan menentukan jenis kecerdasan anak di sertai alternatif karir untuk mengembangkan bakatnya.

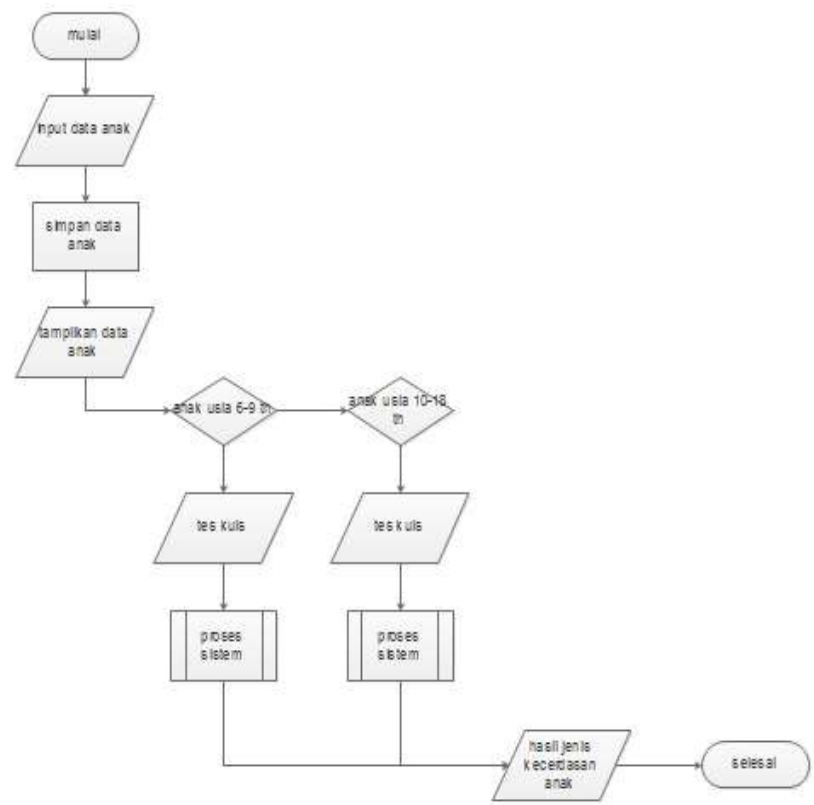

Gambar 2 Gambar Flowchart Alur Sistem 
b. DFD sistem pakar

Menjelaskan alur data anak yang harus diinputkan sebelum melakukan tes kuis yang akan diproses oleh system sehingga menghasilkan data report jenis bakat anak.

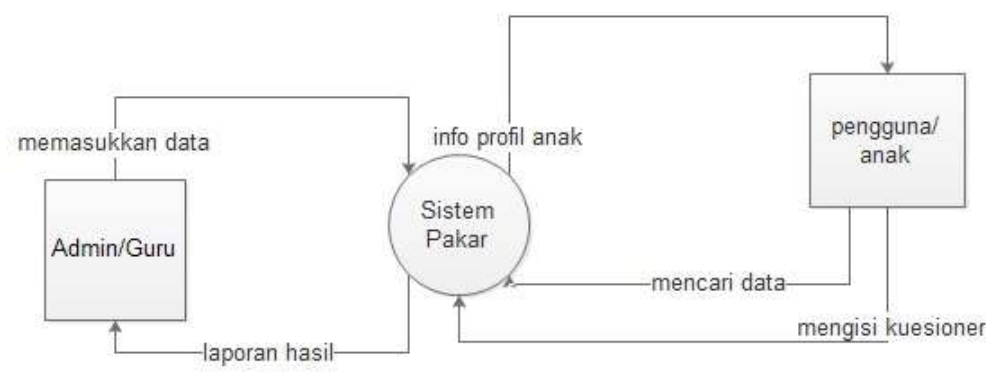

Gambar 3 Gambar DFD Sistem

\section{Hasil dan Pembahasan}

4.1 Perancangan Interface Aplikasi

Perancangan interface Sistem Pendukung Keputusan ini dibangun dengan bahasa pemprograman visual basic 6.0 enterprice edition. Adapun sebagian bentuk perancangan form yang dibutuhkan adalah sebagai berikut :

a. Rancangan tampilan menu utama

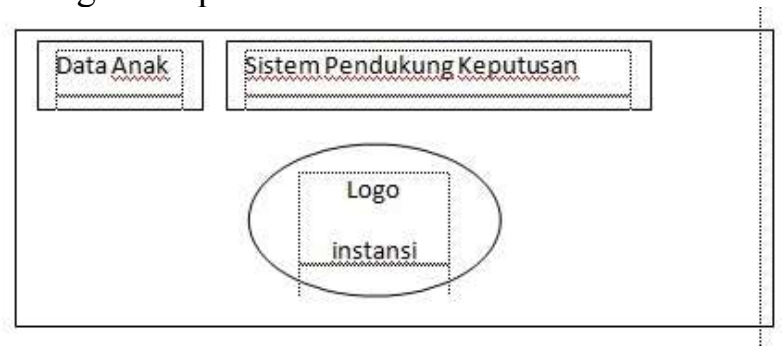

Gambar 4 Gambar Rancangan Menu Utama

b. Rancangan form input data anak

Perancangan ditujukan untuk pengisian data anak yang akan melakukan tes pengenalan bakat dan minat.

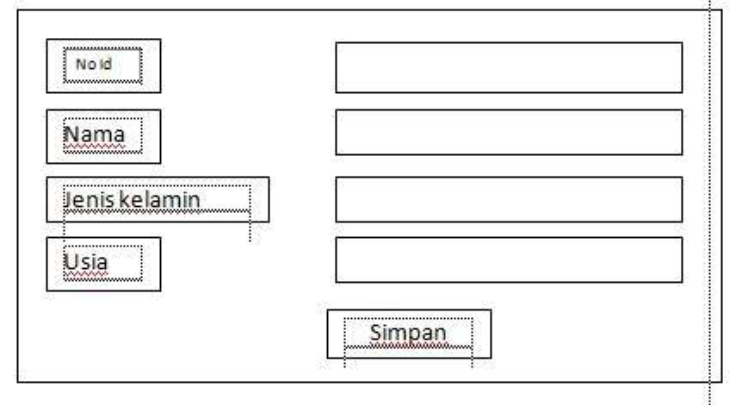

Gambar 5 Gambar Rncangan Form Input Data Anak 
c. Rancangan form kuesioner

Berupa form yang menyajikan beberapa pernyataan untuk dipilih oleh user untuk menentukan bakat dan minat anak.

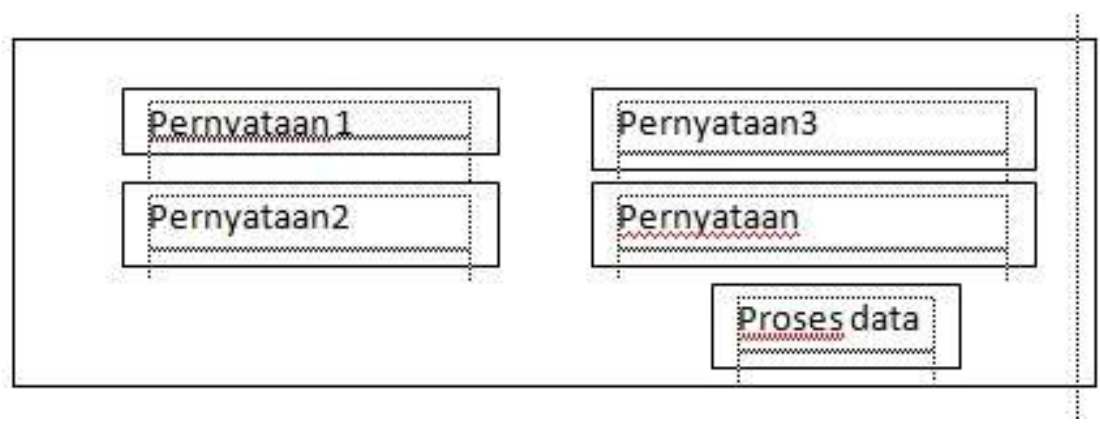

Gambar 6 Gambar Rancangan Form Kuis

\subsection{Hasil Interface Aplikasi}

Setelah dilakukan perancangan interface, dilakukan pengujian untuk melihat apakah hasil perancangan dapat berjalan sesuai harapan. Adapun sebagian hasil yang didapatkan adalah sebagai berikut :

a. Tampilan form menu utama

Menampilkan menu yang dapat diakses oleh user ketika pertama kali membuka program.

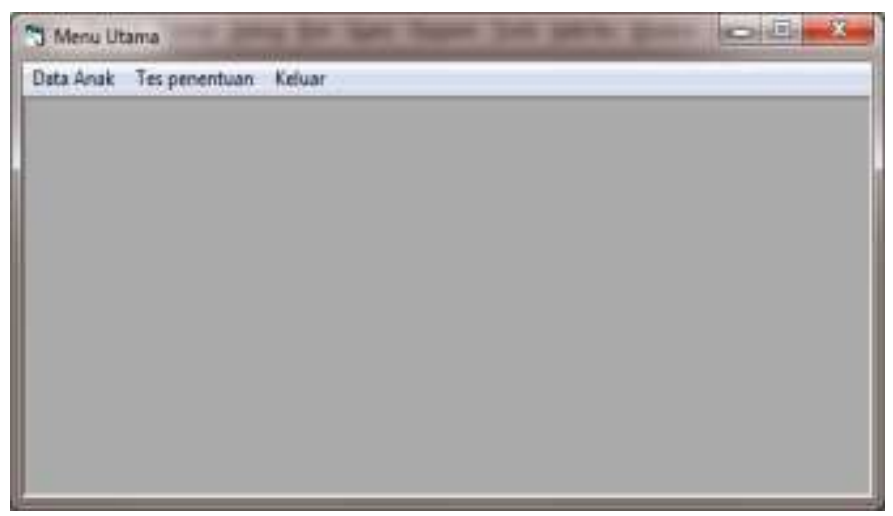

Gambar 7 Gambar Form Menu Utama

b. Tampilan form tambah data anak

Form yang harus diisi data anak yang akan melakukan tes kuis untuk diketahui jenis kecerdasannya.

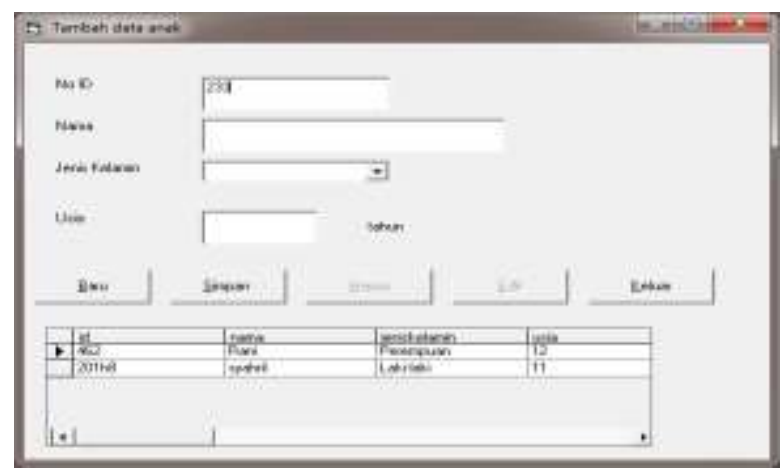

Gambar 8 Gambar Form Input Data Anak 
c. Tampilan form kuis

Form berisi kuis pernyataan yang harus dipilih salah satu untuk menentukan jenis kecerdasan anak.

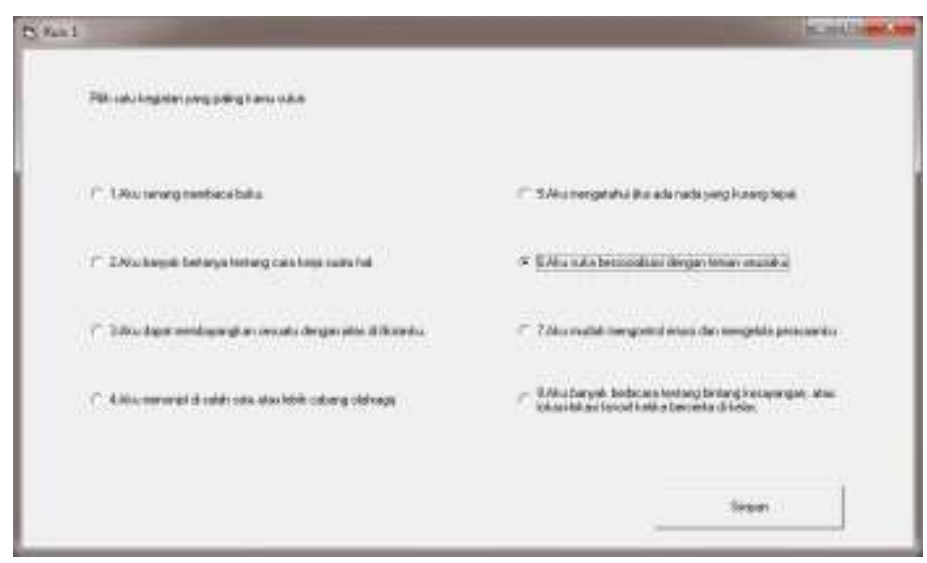

Gambar 9 Gambar Form Kuesioner

d. Tampilan laporan hasil tes

Menampilkan laporan hasil tes yang sudah dilakukan.

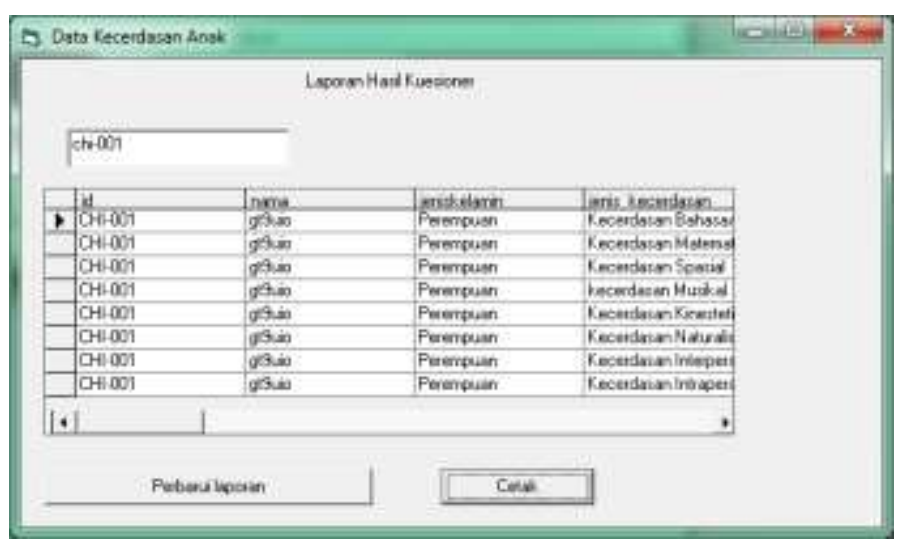

Gambar 10 Gambar Laporan Hasil Tes

\section{Kesimpulan}

Penerapan metode forward chaining dalam system pakar pengenalan bakat dan minat ini diperoleh keterangan mengenai jenis kecerdasan anak yang diimplikasikan pada jenis bakat dan minat anak untuk alternatif karir yang bisa diterapkan guna pengembangan bakat anak.

Hasil pengenalan bakat anak berdasarkan akuisisi pengetahuan dari pakar yang bersangkutan menunjukkan system ini telah teruji validitasnya untuk mengenalkan jenis kecerdasan dan alternatif bakat anak. 


\section{DAFTAR PUSTAKA}

Ahmadi, A. dan Sholeh M., 2005, Psikologi Perkembangan, PT. Rineka Cipta, Jakarta.

Arhami, M, Konsep Dasar Sistem Pakar, Yogyakarta: Andi, 2005.

Kumar, Ela. 2008. Artificial Intellegenc. New Delhi. LK. International Publishing House Pvt. Ltd.

Kusrini. 2008, Aplikasi Sistem Pakar Menentukan Faktor Kepastian Pengguna dengan Metode Kuantifikasi Pertanyaan, ANDI, Yogyakarta.

Lucy, Bunda. 2016. Panduan Praktis Tes Minat \& Bakat Anak. Penebar Plus, Jakarta.

McLeod, Raymond. (1996) : Sistem Informasi Manajemen. Jakarta : PT. Prenhallindo.

Sutojo, T., Mulyanto, Edi. dan Suhartono, Vincent. 2011. Kecerdasan Buatan, Andi, Yogyakarta.

Turban, Efraim. Aranson, Jay, E. dan Liang, Ting-Peng. Alih bahasa oleh Primaningrum, Siska. 2005, Decision Support Systems and Intelligent Systems, $7^{\text {th }}$ edition, Prentice Hall Internasional, Inc., USA.

T Sutojo, Kecerdasan Buatan, Rini W Benedicta, Ed. 2011. Semarang, Indonesia: ANDI Yogyakarta, 